\title{
RESEARCH ON THE METHODS OF QUALITY INSPECTION FOR PUBLISHED CHARTS BASED ON ENTITY RULES AND CARTOGRAPHIC SPECIFICATIONS
}

\author{
Zhao.haitao $^{\mathrm{a}}$, Li. xuefang ${ }^{\mathrm{b}}$, Gao. Xiaorong ${ }^{\mathrm{c}}$
}

\author{
${ }^{a}$ National Quality Inspection and Testing Center for Surveying and Mapping Products, Lianhuachi west Road No.28, Haidian \\ District,Beijing City, China - zhaoht@sbsm.gov.cn \\ ${ }^{\mathrm{b}}$ Beijing University of Civil Engineering and Architecture, Zhanlanguan Road No.1, Xicheng District ,Beijing City, China- \\ lixuefang@bucea.edu.cn \\ ${ }^{\text {C }}$ GanSu Provincial Geomatics Center, Donggang west Road No.793, Chengguan District ,Lanzhou City, China
}

Key words: digital nautical charts, quality inspection, rule database, cartographic specification, entity rule, knowledge representation

\section{ABSTRACT:}

For Chinese paper charts, no standards are made yet, quality of paper charts are controlled by "there-level inspection" with naked eyes at present. This method has many disadvantages like more errors, more omissions, low efficiency and resource wastes etc. But paper charts can not be totally replaced by electronic charts in a short time. Thus, the research on new quality inspection method for paper charts in digital age is absolutely necessary. Aiming at the production of paper charts in digital environment, a new quality inspection method based on entity rules and cartographic specifications is put forward in this paper.

Firstly, considering the fact that updating speed of charts database is closely related to the changing speed of maritime objects, each category of maritime features are analyzed from different aspects including their attributes, symbols, entity rules, changing features, etc. Based on this, features are classified into three categories according to their changing features to make sure that proper quality inspection method will be applied to certain features. The three categories are as follows: low changing speed, fast changing speed with regulations, fast changing speed without regulations. At the same time, rules of each feature and its relationships with some other features are analyzed, too, for all those changing speed and rules, relationships are the most important factors when design inspection methods for each kind of features. Secondly, the concept of inspection method based on entity rules and cartographic specifications are introduced.

\section{INTRODUCTION}

The paper charts publishing technologies and processes undergone great changes with the rapid development of information technology. The widely used of Chart mode of production which based on chart database made the chart published quality testing methods and content changed essentially.

In order to control the quality of charts effectively, many researchers have launched the quality control methods on published charts in deep. Sun Wanmin put forward the core content of the chart publication quality control by analyzing the new concept paper chart production of new methods, new tools and new processes. In his research, the control approach is divided into the production process quality control, the Original quality control and the quality of the map files control [Sunwan Min et al, 2002].This study set the framework for the chart quality control. On this basis, Li Jing analysis macro approaches of quality control in various production processes. These methods include improving the data structure, reducing the production process, review and proofreading; strengthen the construction of product specifications [Jing et al, 2007]. At the same time, other studies have focused primarily on quality testing and control processes in particular. For example, Wang Wenshan $\mathrm{He}$ is mainly taken measures from the evaluation of cartographers' performance and incentive to improve the quality of charts . [Wang Wenshan, 2003],Li Hanrong mainly take account of the impact of the precision control of marine surveying and mapping results to improve the quality of the chart [Li Hanrong et al, 2004].

However, in the actual production, the contrast method was being used for detection, digitized data that is drawn by a plotter, then overlay it with the original map, In the end, to determine the error by obvious objects measurement [Lau Chun-congruent, 2005], the method that automatically detects by computer program was not frequently used. Because there are many shortcomings in this method, such as numerous mistakes, Duplication of effort,inefficiency, a digital environment testing procedures and appropriate intervention method should be developed to meet the need of chart quality control detection .

\section{CHART ELEMENTS ANALYSIS OF THE MAPPING SPECIFICATION}

Based on the Digital Nautical Chart Elements Code provided, chart elements include control points, magnetic elements, natural geographic elements, artificial features, landmark features, ports, tides and currents, depths, substrates, rocks, wrecks and obstacles, offshore facilities, channels, regional boundaries, navigation marks, contour decoration elements and other elements. Analysis and research of a series of chart mapping specifications like Symbols, Abbreviations and Terms Used on Chinese Charts (GB 12319-1998), Specifications for Chinese Nautical Charts (GB 12320-1998), Digital Charts Data Dictionary and Digital Chart Production Management Regulations. Various chart elements change characteristics and mapping specifications are summarized as follows.

\subsection{Control Points}

(1) As the basis of positioning, control point is characterized by its invariance.

(2) According to the mapping specification, control point represents the control point or elevation point with a significance of navigation orientation on the peak of the hill or island in a nautical chart with scale greater than 1:3000 000 .

(3) Use ring symbol or independent landmark symbol (if the control point is an independent landmark) to represent the control point in the map. 


\subsection{Magnetic Elements}

(1) In the magnetic element, except the annual change rate of local magnetic variation possible to have abnormal phenomenon, geomagnetic field is not easy to change and has a long-term change period. Magnetic declination vary from region, its half period is about 250 years. So the magnetic element is associated with geographic location.

(2) In the chart with scale greater than 1:2 000000 , magnetic variation is represented with circle with direction and magnetic north curve, magnetic variation and annual difference. In the chart with scale smaller than 1:2 000000 , it is represented by curve with equal magnetic variation. Magnetic abnormal area must be indicated in all scale maps and commonly represented by a local magnetic exception region.

\subsection{Natural Geographic Elements}

(1) The coastline changes very slowly relative to chart mapping period. Its erosion back, all the way back or stacked speed is measured in years. Meanwhile, limited to the coastline measurement cycle, it is impossible to change the coastline data very frequently.

(2) Similar to the coastline, beach landform change is a continuous, differentiable process.

(3) River and lake location and shapes determined by the shore line. The similarity of the river line, the lake shore line and the coastline has made similar changes in rivers, lakes and coastline.

(4) Canals and ditches are not easy to change, even if they changed, such as new, changed and removing, that is more easily measured. blue

(5) According to chart schema, the coastline symbols in

(6) According to chart specification, various scale maps should accurately represent the coastline in detail. In the chart with scale greater than 1:200 000, measured shorelines and sketch shorelines are distinguished.

(7) In accordance with the norms of the chart cartography, landform elements are represented in contours, elevation points and other landform symbols such as steep rocky mountain symbol, sand symbol. In the chart with scale greater than 1:500 000 , normally use the contour to represent landform. There are corresponding provisions of the basic contour interval scale.

(8) Use line with direction to represent waterfall.

(9) According to the chart specification, various scale maps should mark big sea rivers and canals, ditches, lakes. River wider than $0.4 \mathrm{~mm}$ draw double lines. Some rivers only draw estuaries at the mouth of the estuary.

\subsection{Artificial Features}

(1) In relative, the single building is not easy to change but easy to measure and gather the information due to its particular purpose or public service. Building zone are changes frequently and no rules to follow.

(2) In general, roads, railways, airports are all uneasy to change, only low-level road may disappears. High-level road such as main roads, highways and railways, airports are unlikely to disappear but to broaden or create new ones. For new highway, railway, airport, information gathering and measurement are very easy.

(3) According to the chart mapping specification, various scale maps only mark residents within $150 \mathrm{~mm}$ away from shore. In the 1:100 000 map, select township residents, the village and navigation orientation significance houses. Residential areas are represented according to proportion or by circle symbol.
(4) Rail and road should have been built in various scale maps. Cut-off point in 10 million, 20 million and 50 million, means the road in different importance in the scale interval. In scale greater than 200000 map represents the coast near the airport.

\subsection{Landmark Features}

(1) Generally, the changes of the landmark features are no rules to follow, in particular real-world entities such as independent trees.

(2) Scale greater than 1:200 000 map should be mark landmarks, 500,000 and more small-scale maps usually do not need to. The scale between 200000 and 490000 optionally represent significant buildings along the coast. Use symbols to represent landmark features as possible. No symbol landmark use circle symbol with category name to represent.

\subsection{Ports}

Port facilities, management and service facilities should be well documented, easy access to changed information.

\subsection{Tides and Currents}

(1) Ocean currents are permanent or seasonal seawater horizontal flow. Its speed and direction are relatively stable. Sea currents are large scale horizontal flow of water along a certain direction, but change more frequently.

(2) Tides and currents in our country charts are represented in tide tables, table of the trend, trend chart, as well as trends and currents schematic symbols.

(3) Characteristics of its own variable determined that the representation of the tides and currents are schematically. Tide table for mariners tidal, can be used to calculate roughly the tide of the sea, high tide, similar to the trend of the table and the trend. The extent and location of said trends and currents of the flood tide, ebb current, currents, ocean currents, rapids and whirlpool symbol are approximate. The place to list the trend information is designated symbols.

(4) For the elements of tides and currents, using a computer to achieve its quality testing is simple and feasible just with the tide gauge stations and other related departments to provide accurate information to contrast.

\subsection{Depths}

(1) The sweeping survey area and the location of the dredging area and related information are easily obtained from the maritime sectors. Depth changes in no law, and the location of the deep line is not fixed coordinate approximate location, but the depth relate with the location. Chart quality testing can be done based on this.

(2) On the chart use water depth annotation, regional boundaries (dredging area boundaries, sweeping maritime limit) to represent the depth of the sea.

\subsection{Substrates}

(1) In addition to parts of the elements, such as the instability of sand ripples, most of substrates are stable and uneasy to change.

(2) Substrates in the chart are represented by substrate annotation, such as "sand", "mud", "clay", "silt", "stone", "grind", "shan", "shell", and outlined ranged symbol represent the distribution range of seaweed and sand ripples. Dry beach represents more accurate range. In addition, with the specific adjective annotation (including English annotation) represents in more detail feature, such as "fine" sand, "broken", "soft". 


\subsection{Rocks, Wrecks and Obstacles}

The rocks are stable. With the development of submarine detection, new rocks may be found; the wreck changes irregularly, new vessel accidents or old wreck salvage may changes. Obstacle fishing equipment changes when the season changes, and the mariculture, turbulence is less likely to change.

\subsection{Offshore Facilities}

(1) Offshore facility is fixed element.

(2) Submarine cable area, power line area, oil and gas pipeline area are represented with submarine cable symbol and oil, gas pipeline symbol in groups.

\subsection{Channels}

As a centerline positioning entity, even the fairway boundaries or substrate slowly changes, its own position and the extension are still uneasy to change.

\subsection{Boundaries}

Most of boundaries are completely fixed, such as borders, the international date line, the baseline of the territorial sea, the exclusive economic zone boundary, the customs boundaries. Part of the boundary of the area change is usually obtained relevant information from the relevant maritime administration departments.

\subsection{Navigation Aids}

All navigation aids are unified storaged and unified managed. Similar to the control point, it has specialized database, management and maintenance mechanism. And use information that the relevant department offered to test the quality.

\subsection{Service Facilities}

(1) The information of the service facilities must be easily obtained to update.

(2) Service facilities are normally represented in fixed point symbol with notation.

\subsection{Contour Decoration Elements}

These kinds of elements are completely fixed and they have a specific format.

\section{THE ESTABLISHMENT OF THE RULE BASE ABOUT THE CHART QUALITY TESTING}

\subsection{The methods with different Changes characteristic} chart elements of quality testing methods

Different characteristics of the elements, their update rate, human-edited frequently are not same, thereby affecting its prone to error type, and quality testing for the type of error. For some hard to change, in other word more stable elements, the use of rule base repository detection and maintenance of good information library is now potential resistance; prone to changes in the elements, update the use of rule-based detection its relations with the surrounding elements whether correct while utilizing the information database to detect their graphical representation. Overall, consider the following aspects:

(1) The presence or absence of elements and how to take the elements;

(2) The representation of the elements;

(3) The relationship between the elements;

Take Beacon to the example: table3-1 Beacon quality testing(part)

\begin{tabular}{|c|c|c|c|}
\hline $\begin{array}{l}\text { The aspects of } \\
\text { consideration }\end{array}$ & Type of error & Detail information & $\begin{array}{l}\text { The aspects of } \\
\text { consideration }\end{array}$ \\
\hline \multirow{2}{*}{$\begin{array}{l}\text { The selection of } \\
\text { Navigation mark }\end{array}$} & $\begin{array}{l}\text { select the things Should } \\
\text { not be selected }\end{array}$ & $\begin{array}{l}\text { A scale below a } \\
\text { certain level } \\
\text { elements should not } \\
\text { be shown }\end{array}$ & \multirow{2}{*}{ Mapping specification } \\
\hline & $\begin{array}{l}\text { The right things are not } \\
\text { be selected }\end{array}$ & $\begin{array}{l}\text { Above a certain } \\
\text { level in a scale } \\
\text { factor must be } \\
\text { expressed }\end{array}$ & \\
\hline $\begin{array}{l}\text { The Representation of } \\
\text { Navigation mark }\end{array}$ & $\begin{array}{ll}\text { The } & \text { beacon } \\
\text { corresponding } & \text { symbol } \\
\text { error } & \end{array}$ & $\begin{array}{l}\text { Number of symbols } \\
\text { used to represent the } \\
\text { beacon symbols and } \\
\text { standard library } \\
\text { does not correspond } \\
\text { to each other }\end{array}$ & Mapping specification \\
\hline $\begin{array}{c}\text { The relationship of the } \\
\text { beacon and the regions } \\
\text { in which they are } \\
\text { located }\end{array}$ & $\begin{array}{l}\text { Buoy is not in the } \\
\text { waters, but on land }\end{array}$ & $\begin{array}{l}\text { Buoy itself the } \\
\text { elements in the } \\
\text { waters, due to } \\
\text { misuse of the digital } \\
\text { environment, } \\
\text { mobile, may be have } \\
\text { an error }\end{array}$ & Substantive Rules \\
\hline
\end{tabular}

3.2 The establishment of the rule base about The chart quality testing

Based on the above analysis, which means that the contents need quality detection rule base can be divided into two categories:

( 1 ) Chart elements, the elements of mapping specification, substantive rules, quality test results, and the basic properties of description;

(2) To judge by elements of cartography, composed of elements to judge the substantive rules, by the above judgment inference quality detection results in a series of rules.

According to the division of these two types of content, they can be divided into the information base and rule base.

\subsubsection{The establishments of information}

Information base mainly describe the chart elements, elements of drawing specifications, substantive rules, test results and other information. The corresponding relationship between code for drawing a specific chart element and its substantive rules, even the detection results were correlated by a foreign key. Information database in tabular form which is stored in the database, each field represents the knowledge attribute. Information database is essentially the standard library; it was established, including the standard mapping elements and substantive rules of information. Taking the drawing contour table for example, the depth of the updates may be caused by the original drawing of contour depth point position error, so after the update depth point, you can use rules to detect the correctness of the bathymetric position, so as to draw contour points according to the depth of water 。

table3-2 Bathymetric mapping specification information database of information table of the field design

\begin{tabular}{|c|c|c|c|c|l|}
\hline Field & name & type & Width & $\begin{array}{c}\text { Example } \\
\text { values }\end{array}$ & \multicolumn{1}{|c|}{ Remark } \\
\hline ysID & $\begin{array}{c}\text { Elements } \\
\text { encoding }\end{array}$ & char & 8 & 18020101 & $\begin{array}{l}\text { With the ID number of } \\
\text { the elements of a one- } \\
\text { to-one correspondence }\end{array}$ \\
\hline ysdm & $\begin{array}{c}\text { Elements } \\
\text { code }\end{array}$ & char & 6 & 180201 & $\begin{array}{l}\text { According to the } \\
\text { digital chart elements } \\
\text { code }\end{array}$ \\
\hline txlx & Graph type & char & 1 & L & P, L, A or T \\
\hline xhlx & Line type & char & 2 & 实 & Said solid line to the \\
\hline xhcx & $\begin{array}{c}\text { Line } \\
\text { thickness }\end{array}$ & float & $\begin{array}{c}2 \text { decimal } \\
\text { places }\end{array}$ & $0.15 \mathrm{~mm}$ & $\begin{array}{l}\text { According to } \\
\text { "Regulations" of the } \\
\text { Chinese chart schema }\end{array}$ \\
\hline xhys & $\begin{array}{c}\text { Line } \\
\text { color }\end{array}$ & RGB & $(\mathrm{R}, \mathrm{G}, \mathrm{B})$ & $\begin{array}{c}\text { eg } \\
(0,0,100)\end{array}$ & $\begin{array}{l}\text { RGB or CMYK } \\
\text { Color space }\end{array}$ \\
\hline shsz & $\begin{array}{c}\text { Water } \\
\text { depth }\end{array}$ & int & & 5 & Units of "m" \\
\hline sszj & Depth of & $(\mathrm{x}, \mathrm{y})$ & $(\mathrm{x}, \mathrm{y})$ & $(\mathrm{x}, \mathrm{y})$ & For judging the \\
\hline
\end{tabular}




\begin{tabular}{|c|c|c|c|c|c|}
\hline & Note & $\begin{array}{c}\text { Coordinate } \\
\text { pair }\end{array}$ & & & $\begin{array}{l}\text { contour representation } \\
\text { is correct or not }\end{array}$ \\
\hline hcql & $\begin{array}{l}\text { on the left } \\
\text { side of } \\
\text { Depth of } \\
\text { water } \\
\text { buffer } \\
\text { coding }\end{array}$ & L & $\begin{array}{l}\text { By the depth } \\
\text { of water line } \\
\text { control pints. }\end{array}$ & $18020101 \mathrm{~L}$ & $\begin{array}{l}\text { Association of another } \\
\text { table, to judge the } \\
\text { contour and the } \\
\text { surrounding water } \\
\text { note relations are } \\
\text { correct }\end{array}$ \\
\hline hcqr & $\begin{array}{l}\text { on the } \\
\text { right side } \\
\text { of Depth } \\
\text { of water } \\
\text { line buffer } \\
\text { Coding }\end{array}$ & L & $\begin{array}{l}\text { By the depth } \\
\text { of water line } \\
\text { control points. }\end{array}$ & $18020101 \mathrm{R}$ & $\begin{array}{l}\text { Association of another } \\
\text { table, to judge the } \\
\text { contour and the } \\
\text { surrounding water } \\
\text { note relations are } \\
\text { correct }\end{array}$ \\
\hline
\end{tabular}

\subsubsection{ESTEBLISHMENT OF THE RULES}

The rule base describes quality inspection results by understanding elements of the chart. Basic field of rule table has conditions in terms of the condition name and condition number, and there are conclusion name and conclusion number; in multiple conditions, also need the importance of description of the condition in the rule of (conditional weight) and the conclusion of a minimum requirement (rule threshold.).There are several methods to considering the conclusion is right (one method is enough), some methods must satisfy rules in the same time, and the combination of the phenomenon between some conditions of these parallel rules, meet certain combination relations, than we can say it right. So also need to increase several fields such as: methods, parallel rules, groups, groups within the threshold to describe these relations.

Rule description is ultimately to the rules of a physical record to achieve, a rule is sometimes necessary to use multiple records to describe, the more complex of the rules, the more corresponding record may have. Taking bathymetric quality inspection conclusion acontour drawing error" as an example.

There are three ways to launch conclusions isobaths delineation error.

The first method According to "China nautical charts specification" not express basic isobaths $20 \mathrm{~m}$ Isobaths in more than 1:100 million scale map;

The second method Depth isobaths itself compared coverage and isobaths buffer value of water depth on both sides, not in between the two;

This method is of two parallel rules, namely the isobath left buffer covered under the depth value and the right buffer covered under the depth value is compared with the value of water depth contour itself, all the water side of the value should be less than the contour depth value, one side of all the depth value should be greater than bathymetric depth value, two conditions and one does not meet, you description of contour drawing error.

The third method Such as depth contour is not closed (isobaths both coordinate position inconsistent) with the adjacent isobaths distance of not less than $1 \mathrm{~mm}$.

This approach is also two parallel rules, different from the second method is that this method must satisfy two conditions. Isobaths must first be closed, followed by waiting for the deep

line is disconnected at the point adjacent isobath distance greater than $1 \mathrm{~mm}$, two conditions are true.

table3-3 Derivation of quality inspection conclusion rules of contour drawing error

\begin{tabular}{|c|c|c|c|c|c|c|c|c|c|}
\hline CNo & CName & MT & PR & CN & CDN & CV & CC & TIG & TOR \\
\hline $\begin{array}{l}1802 \\
\text { 01aa }\end{array}$ & $\begin{array}{l}\text { Contour } \\
\text { drawing } \\
\text { error }\end{array}$ & 1 & 1 & $\begin{array}{l}1802 \\
0101\end{array}$ & $\begin{array}{l}\text { The lack } \\
\text { of basic } \\
\text { 20 meters } \\
\text { isobaths }\end{array}$ & 0 & 1 & 1 & 1 \\
\hline 1802 & $\begin{array}{l}\text { Contour } \\
\text { drawing } \\
\text { error }\end{array}$ & 2 & 1 & $\begin{array}{l}1802 \\
0102\end{array}$ & $\begin{array}{l}\text { On the } \\
\text { left side } \\
\text { of } \\
\text { buffer } \\
\text { The error } \\
\text { value of } \\
\text { water } \\
\text { depth }\end{array}$ & 0 & 1 & 1 & 1 \\
\hline 1802 & $\begin{array}{l}\text { Contour } \\
\text { drawing }\end{array}$ & 2 & 1 & $\begin{array}{l}1802 \\
0103\end{array}$ & $\begin{array}{l}\text { The right } \\
\text { side of }\end{array}$ & 0 & 1 & 1 & 1 \\
\hline
\end{tabular}

\begin{tabular}{|c|c|c|c|c|l|l|l|l|l|}
\hline & error & & & $\begin{array}{l}\text { buffer } \\
\text { Depth of } \\
\text { water } \\
\text { error }\end{array}$ & & & \\
\hline 1802 & $\begin{array}{l}\text { Contour } \\
\text { drawing } \\
\text { error }\end{array}$ & 3 & 1 & $\begin{array}{l}1802 \\
0104\end{array}$ & $\begin{array}{l}\text { Contour } \\
\text { unclosed }\end{array}$ & 0 & 1 & 2 & 1 \\
\hline 1802 & $\begin{array}{l}\text { Contour } \\
\text { drawing } \\
\text { error }\end{array}$ & 3 & 1 & $\begin{array}{l}1802 \\
0105\end{array}$ & $\begin{array}{l}\text { And the } \\
\text { adjacent } \\
\text { contour } \\
\text { distance } \\
\text { is greater } \\
\text { than 1mm }\end{array}$ & 0 & 1 & 2 & 1 \\
\hline
\end{tabular}

NOTE:

CNo: Conclusion No.

CName: Conclusion Name.

MT: method.

PR: Parallel Rule.

$\mathrm{CN}$ : Condition No.

CDN: Condition Name.

CV: Condition Value.

CC: Conditions Constituencies.

TIG: Threshold In Group.

TOR: Threshold Of The Rule.

\section{CONCLUSIONS}

This paper presents a mapping specification, taking into account the need for a chart substantive rules and chart elements chart elements quality detection methods, the chart elements in accordance with the characteristics of the speed of change, divided into changes slowly, change frequently, but there is a pattern or evidence can be check and change frequently and no rules to follow several types, taking into account the relationship between the elements of rules and elements, to explore ways to establish quality detection rule base elements specific to the selection rules, express rules and physical knowledge rules in the rules library organization, a useful exploration for the detection and control of publishing in the digital environment, the quality of the paper chart

\section{REFERENCES}

[1]. GB 12319-1998 Chinese chart diagram, State Bureau of quality and technical supervision, 1998.12.15.

[2]. GB 12320-1998 specifications for Chinese nautical charts, the State Bureau of quality and technical supervision, 1998.12.15.

[3] . Sunwan Min, SUN Qun, Xiao Qiang, chart publication quality control Technical Approaches, ocean mapping, Volume 22, Issue 4, 2002.7.

[4]. Li Hanrong, Chen Hung row, Venus, ocean mapping and digital chart achievements of quality control, the China Institute of Surveying and Mapping sixteenth Ocean Mapping Symposium, Received Date 2004, July 12.

[5] . Li Jing, Sun Wanmin, digital chart production technology system and quality control process analysis, mapping the ocean, Volume 27, Issue 1, 2007.1。

[6]. Wang Wenshan, talking on the chart quality management innovation, integrated Symposium of the 15th session of the Ocean Mapping of the Chinese Institute of Surveying and Mapping, Received July 31, 2003.

[7]. Liu Zhenquan, Wang Wenshan, a preliminary study of the geographic information system data quality and its control, the marine surveying and mapping of the seventeenth conference of the Chinese society of Surveying and mapping in July 5, 2005, received date.

[8]. Li Shujun, Digital Chart quality testing and evaluation system design methods to explore, Ocean Mapping, 20013. 
[9]. Li Xiaoming, quality detection method based on the Digital Chart of the standard library, Wuhan University master's degree thesis, 2007.6。

[10]. Sunwan Min, Ling Yong, SUN Qun, reduce the paper charts redundancy generated by the database link, Ocean Mapping, 20013.

[11]. Sunwan Min, SUN Qun, Zhang Baoming, Shen Xiao Qiang, charts publication quality detection system design and implementation, Ocean Mapping, Vol 24, Issue 3, 2004.5.

[12]. Sunwan Min Yuan Sheng Jian, MicroStation environment Chart Production data quality control, China Institute of Surveying and Mapping sixteenth Ocean Mapping Symposium, Received June 18, 2004. 